\title{
Klasifikasi Jenis Pencabutan Layanan oleh Pelanggan Indihome Menggunakan Metode Chi-Square Automatic Interaction Detection
}

\author{
Siti Khodijatunnuriyah ${ }^{1}$, Hasih Pratiwi ${ }^{2}$ \\ ${ }^{1,2}$ Program Studi Statistika, Universitas Sebelas Maret \\ sitinuriyah683@gmail.com, hpratiwi@staff.uns.ac.id
}

\begin{abstract}
Market segmentation is a classic topic in marketing which is never loss its attractiveness. In addition to market segmentation, customer satisfaction is important in the field of marketing. Customer satisfaction is a person's feelings after using goods or services produced by a company. High customer satisfaction shows a company's success in producing goods or services. Statistics provides many tools for segmentation research. One of statistical tool for segmentation research which takes the dependency method as an approach is Chi-Squared Automatic Interaction Detection (CHAID) analysis. CHAID analysis would provide decision tree like diagram which provide information about degree of association from dependent variable to the independent variables and the information about segments characteristic. In this case, the CHAID analysis is used to determine the type of service revocation segmentation by Indihome customers. Based on CHAID analysis, 25 segmentations were obtained, which consisted of revocation of the downgrade category of 45314 customers and the number of revocation of the Churn Out category by 11137 customers.
\end{abstract}

Keywords : market segmentation, customer satisfaction, CHAID, Indihome

\section{Pendahuluan}

Semakin banyaknya masyarakat yang menggunakan alat komunikasi, maka kualitas pelayanan menjadi sesuatu yang penting untuk memenangkan persaingan. Bukan hanya perangkat seluler yang semakin canggih, jaringan internet pun tidak mau kalah, seperti perkembangan teknologi komunikasi seluler di Indonesia yang semakin meningkat dari tahun ke tahun. Seiring berkembangnya zaman, persaingan antar provider jaringan internet di Indonesia khususnya semakin ketat. Setiap provider menawarkan kecepatan akses internet yang lebih baik dari provider lain untuk mengait pelanggan yang lebih banyak. Oleh karena itu, kepuasan pelanggan menjadi sesuatu hal yang penting untuk diperhatikan oleh setiap perusahaan provider. Kepuasan pelanggan merupakan faktor penting untuk mengetahui apakah layanan yang diberikan oleh perusahaan sudah memuaskan pelanggan. Karena banyaknya kategori layanan yang diberikan, pihak Telkom perlu melakukan klasifikasi pelanggan berdasarkan layanan yang digunakannya untuk melihat dan mengenali pelanggan yang melakukan pencabutan berdasarkan kriteria-kriteria yang ada. 


\section{Landasan Teori}

2.1. Profil Perusahaan. PT. Telekomunikasi Indonesia, Tbk (PT. Telkom) merupakan satu-satunya Badan Usaha Milik Negara (BUMN) penyelenggara layanan telekomunikasi dan jaringan terbesar di Indonesia. Seiring berkembangnya zaman serta ilmu pengetahuan dan teknologi, PT. Telekomunikasi Indonesia, Tbk melakukan perubahan dan pengembangan produk Speedy menjadi Indihome Triple Play. Indihome fiber merupakan layanan triple play dari Telkom yang terdiri dari internet fiber atau High Speed Internet (Internet Cepat), Phone (Telepon Rumah), dan Interactive TV (UseeTV Cable).

2.2. Status Pelanggan. Ada dua tipe status pelanggan yang diberikan oleh PT. Telekomunikasi Indinesia, Tbk. yaitu:

1) Status Active

Pelanggan dengan status active merupakan pelanggan yang tidak melakukan pencabutan layanan Indihome.

2) Status Tidak Active

Pelanggan dengan status tidak active merupakan pelanggan yang melakukan mencabutan layanan Indihome. Ada dua jenis pencabutan layanan yang bisa dilakukan oleh pelanggan Indihome, yaitu :

\section{a. Downgrade}

Pencabutan layanan jenis downgrade adalah pencabutan layanan oleh pelanggan Indihome dengan hanya mencabut sebagian layanan yang dia pakai.

\section{b. Churn Out}

Pencabutan layanan jenis churn out adalah pencabutan layanan oleh pelanggan Indihome dengan mencabut seluruh layanan yang dia pakai.

2.3. Data hilang. Data hilang adalah suatu kondisi hilangnya sebagian fitur pada dataset. Data hilang dapat diakibatkan oleh kesalahan sistem maupun human error. Dalam banyak kasus yang berkaitan dengan pengenalan pola maupun klasifikasi, data hilang merupakan permasalahan yang dapat mempengaruhi hasil klasifikasi. Beberapa metode telah dikembangkan khusus untuk menangani data hilang. Salah satu metode tersebut adalah teknik imputasi. Imputasi data adalah memperkirakan nilai pada data 
hilang dengan cara mendapatkan pola dari data yang memiliki fitur lengkap. Beberapa metode imputasi yang populer adalah: Mean, Median/Modus dan klasterisasi.

2.4. Data Mining. Data mining adalah proses yang menggunakan teknik statistik, matematika, kecerdasan buatan, dan machine learning untuk mengekstraksi dan mengidentifikasi informasi yang bermanfaat dan pengetahuan yang terkait dari berbagai database besar [1]. Istilah data mining memiliki hakikat sebagai disiplin ilmu yang tujuan utamanya adalah untuk menemukan, menggali, atau menambang pengetahuan dari data atau informasi yang dimiliki. Data mining, sering juga disebut sebagai Knowledge Discovery in Database (KDD). KDD adalah kegiatan yang meliputi pengumpulan, pemakaian data, historis untuk menemukan keteraturan, pola atau hubungan dalam himpunan data berukuran besar [2]. Ada beberapa teknik yang dimiliki data mining berdasarkan tugas yang bisa dilakukan yaitu deskripsi, estimasi, prediksi, klasifikasi, klastering, dan asosiasi [3].

2.5. Klasifikasi. Klasifikasi adalah proses untuk menemukan sebuah model atau fungsi yang menjelaskan dan mencirikan konsep atau kelas data, untuk kepentingan tertentu. Dalam klasifikasi, variabel tujuan bersifat kategorik. Misalnya mengklasifikasikan pendapatan dalam tiga kelas, yaitu pendapatan tinggi, pendapatan sedang, dan pendapatan rendah. Terdapat beberapa teknik klasifikasi dalam data mining yaitu Regresi Logistik, Nä̈ve Bayes, Neural Network, dan Decision Tree.

2.6. Decision Tree. Decision tree merupakan salah satu metode klasifikasi yang menggunakan representasi struktur pohon (tree) dengan setiap node merepresentasikan atribut, cabangnya merepresentasikan nilai dari atribut, dan daun merepresentasikan kelas. Node yang paling atas dari decision tree disebut sebagai root [4].

Terdapat tiga jenis node pada algoritma decision tree, meliputi :

a. Node akar

Node akar merupakan node paling atas, pada node ini tidak ada input dan bisa tidak mempunyai output atau mempunyai output lebih dari satu.

b. Node Cabang

Node cabang merupakan node percabangan, pada node ini hanya terdapat satu input dan mempunyai output minimal dua. 


\section{c. Node Akhir}

Node akhir atau node terminal, merupakan node akhir, pada node ini hanya terdapat satu input dan tidak mempunyai output.

Terdapat beberapa persyaratan yang harus dipenuhi dalam penerapan algoritma decision tree meliputi :

a. Algoritma decision tree merepresentasikan supervised learning, dan oleh karena itu membutuhkan variabel target preclassified.

b. Training data harus bervariasi.

c. Kelas atribut target harus diskrit

Beberapa algoritma terkait decision tree yaitu Classification and Regression Tree (CART), Algoritma C4.5, C5.0, dan Chi-Squared Automatic Interaction Detection (CHAID).

2.7. Chi-Squared Automatic Interaction Detection (CHAID). CHAID digunakan untuk membentuk segmentasi yang membagi sebuah sampel menjadi dua atau lebih kelompok yang berbeda berdasarkan sebuah kriteria tertentu. Hal ini kemudian diteruskan dengan membagi kelompok-kelompok tersebut menjadi kelompok yang lebih kecil berdasarkan variabel variabel independen yang lain. Prosesnya berlanjut sampai tidak ditemukan lagi variabel - variabel independen yang signifikan secara statistik. Segmensegmen yang dihasilkan akan bersifat saling lepas yang secara statistik akan memenuhi kriteria pokok segmentasi dasar [5]. Hasilnya juga akan memberikan peringkat pada variabel yang merupakan variabel independen paling signifikan sampai yang tidak signifikan.

CHAID memilih variabel independennya atas dasar uji chi-square antara kategori variabel yang tersedia dengan kategori variabel dependennya (seperti yang terdapat pada statistika dasar bahwa uji chi-square merupakan uji non parametrik yang sesuai untuk menguji hubungan antar variabel yang berbentuk kategori) [6].

Dalam analisis CHAID variabel yang digunakan dibedakan atas variabel terikat (variabel dependen) dan variabel bebas (variabel independen). Klasifikasi dalam CHAID dilakukan berdasarkan pada hubungan yang ada antara kedua variabel tersebut, oleh karena itu CHAID termasuk dalam metode dependensi dalam menentukan segmentasi. Algoritma CHAID digunakan untuk melakukan penggabungan dan pemisahan kategori- 
kategori dalam variabel yang akan di analisis [7]. Secara garis besar algoritma ini dapat dibagi menjadi tiga tahap, yaitu penggabungan (merging), pemisahan (splitting), dan penghentian (stopping).

1) Penggabungan (Merging)

a) Bentuk tabel kontingensi dua arah untuk masing-masing variabel independen dengan variabel dependen.

b) Hitung statistik chi-square untuk setiap pasang kategori yang dapat dipilih untuk digabung menjadi satu, untuk menguji kebebasannya dalam sebuah sub tabel kontingensi 2 x $J$ yang dibentuk oleh sepasang kategori tersebut dengan variabel dependennya yang mempunyai sebanyak $J$ kategori. Langkah uji chi square adalah sebagai berikut :

i. Perumusan hipotesis

$H_{0}$ : tidak terdapat hubungan antara kategori $i$ pada variabel independen dan kategori $j$ pada variabel dependen

$H_{l}$ : terdapat hubungan kategori $i$ pada variabel independen dan kategori $j$ pada variabel dependen

ii. Tingkat signifikansi

$\alpha=5 \%$

iii. Daerah Kritis

$H_{0}$ ditolak jika $X^{2} \geq X_{\alpha ;(b-1)(k-1)}^{2}$

iv. Statistik Uji

$$
X^{2}=\sum_{i} \sum_{j} \frac{\left(O_{i j}-E_{i j}\right)^{2}}{E_{i j}}
$$

dengan $O_{i j}$ dan $E_{i j}$ masing-masing adalah frekuensi jumlah pengamatan dan nilai harapan pada baris ke-i dan kolom ke-j.

v. Kesimpulan

c) Untuk masing-masing nilai chi-square berpasangan, hitung nilai p-value berpasangan bersamaan. Diantara pasangan-pasangan yang tidak signifikan, 
gabungkan sebuah pasangan kategori yang paling mirip (yaitu pasangan yang mempunyai nilai chi-square berpasangan terkecil atau nilai $p$-value terbesar) menjadi sebuah kategori tunggal, dan kemudian dilanjutkan ke langkah (d).

d) Periksa kembali kesignifikanan kategori baru setelah digabung dengan kategori lainnya dalam variabel independen. Jika masih ada pasangan yang belum signifikan, ulangi langkah (c). Jika semuanya sudah signifikan lanjutkan ke langkah selanjutnya.

e) Hitung nilai $p$-value terkoreksi Bonferroni didasarkan pada tabel yang telah digabungkan dan nilainya dijadikan taraf uji signifikan. Untuk menentukan persamaan koreksi Bonferroni terlebih dahulu dihitung pengali Bonferroni. Nilai pengali Bonferroni tersebut dihitung berdasarkan tipe variabelnya. Jika skala pengukuran variabelnya merupakan skala ordinal maka nilai pengali Bonferroni dihitung dengan rumus:

$$
B=\left(\begin{array}{l}
c-1 \\
g-1
\end{array}\right)=\frac{(c-1) !}{(g-1) !((c-1)-(g-1)) !}
$$

dengan $c$ adalah banyak kategori variabel independen awal ke- $i$ dan $g$ adalah banyak kategori variabel independen ke- $i$ setelah penggabungan, dan $i=1,2, \ldots, \mathrm{n}$. Apabila skala pengukuran variabelnya adalah skala nominal maka nilai pengali Bonferroni dihitung dengan rumus:

$$
B=\sum_{i=0}^{g-1}(-1)^{i} \frac{(g-1)^{c}}{i !(g-1) !}
$$

Persamaan Bonferroni kemudian dihitung dengan rumus:

$$
\alpha=\frac{\pi}{B}
$$

dengan $\alpha$ adalah comparisom-wise error rate (CWER), $\pi$ adalah family-wide error rate $(F W E R)$, dan B adalah pengali bonferroni. Setelah dilakukan koreksi Bonferroni pada variabel independen yang memiliki lebih dari dua kategori, hitung nilai Chi-Square selanjutnya dengan menggunakan taraf signifikan dari hasil koreksi Bonferroni. 
2) Pemisahan (Splitting)

a) Pilih variabel independen yang memiliki nilai- $p$ terkecil (paling signifikan) yang akan digunakan sebagai split node.

b) Jika nilai- $p$ kurang dari atau sama dengan tingkat spesifikasi alpha, split node menggunakan variabel independen ini. Jika tidak ada variabel independen dengan nilai- $p$ yang signifikan, tidak dilakukan split node dan node ditentukan sebagai node terminal (node akhir).

3) Penghentian (Stopping)

Kembali ke tahap penggabungan untuk variabel selanjutnya kemudian hentikan ketika semua kelompok variabel-variabel telah dianalisis. Setelah tidak didapatkan lagi variabel independen dengan masing-masing kategori yang signifikan, maka pembentukan pohon selesai.

\section{Metode Penelitian}

Data yang digunakan dalam penelitian ini adalah data sekunder, yaiu data pelanggan Indihome yang melakukan pencabutan layanan Indihome pada tahun 2018. Penelitian ini dilakukan di wilayah telekomunikasi (witel) yang masuk dalam cakupan kantor Telkom regional IV Jawa Tengah dan DIY antara lain witel Kudus, Magelang, Pekalongan, Purwokerto, Semarang, Solo, dan witel Yogyakarta.

Data tersebut kemudian dipergunakan sebagai variabel dalam melakukan analisis CHAID. Variabel dalam penelitian ini terdiri dari variabel dependen dan independen sebagai berikut:

a) Variabel Dependen

Variabel dependen yang digunakan dalam penelitian ini adalah jenis pencabutan yang dibagi menjadi dua kategori :

\section{a. Downgrade}

Pencabutan layanan jenis downgrade adalah pencabutan layanan oleh pelanggan Indihome dengan hanya mencabut sebagian layanan yang dia pakai.

\section{b. Churn Out}

Pencabutan layanan jenis churn out adalah pencabutan layanan oleh pelanggan Indihome dengan mencabut seluruh layanan yang dia pakai. 
Volume 2 No. 2 November 2019

b) Variabel Independen

Terdapat tiga variabel independen yang digunakan dalam penelitian ini yaitu:

1) Deskripsi Indihome

$>\quad$ New Indihome

$>\quad$ Old Indihome

$>\quad 3 p$ Indihome Others

$>\quad$ Inet_Tv

$>\quad$ Indihome $2 p$

$>\quad$ Non Indihome

2) Kategori Pelanggan

$>$ Apartmen

$>\quad$ Bisnis

$>\quad$ Dinas Rumah

$>\quad$ Pemerintah/TNI/Polri

$>\quad$ Prime Cluster

$>\quad$ Residential

$>\quad$ Telum

$>\quad$ Wartel

3) Layanan TV

$>\quad$ Groovy Iptv Sd

$>\quad$ New UseeTv Entry Hd

$>\quad$ Paket YesTv Hit Entertainment

$>\quad$ Paket YesTv Hitsport

$>\quad$ Usee Basic Pack Sd

$>\quad$ Usee Starter Pack Sd

$>\quad$ Usee Tv Diamond Sd

$>\quad$ Usee Tv Gold Hd 
Usee Tv Gold Sd

Usee Tv Platinum Sd

Useetv Indihome $H d$

Useetv Indihome Passive

Useetv Indihome $S d$

Useetv Indihome Starer Hd

\section{Hasil dan Pembahasan}

\subsection{Analisis CHAID}

Segmentasi yang dihasilkan oleh analisis CHAID dengan dibantu software IBM SPSS 20.0 pada pelanggan yang melakukan pencabutan layanan di PT Telkom.

Pada diagram pohon hasil analisis CHAID, diperoleh sejumlah 37 node dengan 25 node terminal yang berarti diperoleh 25 klasifikasi pelanggan pencabutan layanan Indihome.

Tabel 1. Klasifikasi pelanggan yang melakukan pencabutan layanan Indihome

\begin{tabular}{ll}
\hline Segmen ke-1 & $\begin{array}{l}\text { Jenis pencabutan layanan Non Indihome pengguna UseeeTv } \\
\text { Indihome Passive dan Usee Starter Pack Sd oleh kategori } \\
\text { pelanggan Residensial serta Pemerintah/TNI/Polri }\end{array}$ \\
\hline Segmen ke-2 & Jenis pencabutan layanan Non Indihome pengguna UseeeTv \\
& Indihome Passive dan Usee Starter Pack Sd oleh kategori \\
& pelanggan Bisnis, Prime Cluster, Apartment, serta Wartel \\
\hline Segmen ke-3 & Jenis pencabutan layanan Non Indihome pengguna New UseeTv \\
& Entry Hd dan Usee Tv Gold Sd \\
\hline Segmen ke-4 & Jenis pencabutan layanan Non Indihome pengguna Useetv \\
& Indihome Starer Hd, Useetv Indihome Sd, dan Useetv Indihome \\
& Hd
\end{tabular}
Segmen ke-5 Jenis pencabutan layanan Indihome $2 P$ pengguna New UseeTv Entry HD, UseeTv Indihome Starer HD, dan UseeTv Indihome $H d$ oleh kategori pelanggan Residensial 
Tabel 1. Klasifikasi pelanggan yang melakukan pencabutan layanan Indihome (lanjutan)

\begin{tabular}{|c|c|}
\hline Segmen ke-6 & $\begin{array}{l}\text { Jenis pencabutan layanan Indihome } 2 P \text { pengguna New UseeTv } \\
\text { Entry } H d \text {, UseeTv Indihome Starer } H d \text {, dan UseeTv Indihome } \\
H d \text { oleh kategori pelanggan Bisnis, Pemerintah/TNI/Polri, } \\
\text { Wartel, serta Telum }\end{array}$ \\
\hline Segmen ke-7 & $\begin{array}{l}\text { Jenis pencabutan layanan Indihome } 2 P \text { pengguna New UseeTv } \\
\text { Entry } H d \text {, UseeTv Indihome Starer } H d \text {, dan UseeTv Indihome } \\
H d \text { oleh kategori pelanggan Prime Cluster, Apartment, serta } \\
\text { Dinas Rumah }\end{array}$ \\
\hline Segmen ke-8 & $\begin{array}{l}\text { Jenis pencabutan layanan Indihome } 2 P \text { pengguna UseeTv } \\
\text { Indihome } S d\end{array}$ \\
\hline Segmen ke-9 & $\begin{array}{l}\text { Jenis pencabutan layanan Indihome } 2 P \text { pengguna Usee Starter } \\
\text { Pack Sd, Usee Basic Pack Sd, Groovy IpTv Sd, Paket YesTv Hit } \\
\text { Entertainment, dan UseeTv Gold Sd }\end{array}$ \\
\hline Segm & $\begin{array}{l}\text { Jenis pencabutan layanan } 3 P \text { Indihome Others dan Old } \\
\text { Indihome pengguna Groovy Iptv dan Paket YesTv Hitsport oleh } \\
\text { kategori pelanggan Residensial, Prime Cluster, serta Apartment }\end{array}$ \\
\hline re-11 & $\begin{array}{l}\text { Jenis pencabutan layanan } 3 P \text { Indihome Others dan Old } \\
\text { Indihome pengguna Groovy Iptv dan Paket YesTv Hitsport oleh } \\
\text { kategori pelanggan Bisnis serta Pemerintah/TNI/Polri }\end{array}$ \\
\hline Segmen ke-12 & $\begin{array}{l}\text { Jenis pencabutan layanan } 3 P \text { Indihome Others dan Old } \\
\text { Indihome pengguna New UseeTv Entry } H d \text { dan UseeTv } \\
\text { Platinum Sd }\end{array}$ \\
\hline Segm & $\begin{array}{l}\text { Jenis pencabutan layanan } 3 P \text { Indihome Others dan Old } \\
\text { Indihome pengguna UseeTv Indihome Passive, Usee Basic Pack } \\
\text { Sd, dan UseeTv Gold Sd }\end{array}$ \\
\hline Segmen ke-14 & $\begin{array}{l}\text { Jenis pencabutan layanan } 3 P \text { Indihome Others dan Old } \\
\text { Indihome pengguna UseeTv Indihome Starer Hd oleh kategori } \\
\text { pelanggan Residensial, Prime Cluster, serta Dinas Rumah }\end{array}$ \\
\hline
\end{tabular}


Tabel 1. Klasifikasi pelanggan yang melakukan pencabutan layanan Indihome (lanjutan)

\begin{tabular}{ll}
\hline Segmen ke-15 & Jenis pencabutan layanan $3 P$ Indihome Others dan Old \\
& Indihome pengguna UseeTv Indihome Starer Hd oleh kategori \\
& pelanggan Bisnis, Pemerintah/TNI/Polri, serta Telum \\
\hline Segmen ke-16 & Jenis pencabutan layanan $3 P$ Indihome Others dan Old \\
& Indihome pengguna UseeTv Indihome Sd, UseeTv Gold Hd, dan \\
& UseeTv Diamond Sd oleh kategori pelanggan Residensial serta \\
& Prime Cluster \\
\hline Segmen ke-17 & Jenis pencabutan layanan 3P Indihome Others dan Old \\
& Indihome pengguna UseeTv Indihome Sd, UseeTv Gold Hd, dan \\
& UseeTv Diamond Sd oleh kategori pelanggan Bisnis, Dinas \\
& Rumah, serta Pemerintah/TNI/Polri
\end{tabular}

\begin{tabular}{ll}
\hline Segmen ke-18 & Jenis pencabutan layanan $3 P$ Indihome Others dan Old \\
& Indihome pengguna UseeTv Indihome Hd dan Usee Starter \\
& Pack Sd oleh kategori pelanggan Residensial, Prime Cluster, \\
& Dinas Rumah, serta Pemerintah/TNI/Polri \\
\hline Segmen ke-19 & Jenis pencabutan layanan 3P Indihome Others dan Old \\
& Indihome pengguna UseeTv Indihome Hd dan Usee Starter \\
& Pack Sd oleh kategori pelanggan Bisnis serta Telum \\
\hline Segmen ke-20 & Jenis pencabutan layanan New Indihome pengguna UseeTv \\
& Diamond Sd \\
\hline Segmen ke-21 & Jenis pencabutan layanan New Indihome pengguna New UseeTv \\
& Entry Hd dan UseeTv Indihome Passive \\
\hline Segmen ke-22 & Jenis pencabutan layanan New Indihome pengguna UseeTv \\
& Indihome Starer Hd \\
\hline Segmen ke-23 & Jenis pencabutan layanan New Indihome pengguna UseeTv \\
& Indihome Sd, UseeTv Indihome Hd, Usee Starter Pack Sd, \\
& UseeT Gold Hd, dan UseeTv Gold Sd oleh kategori pelanggan \\
& Residensial serta Prime Cluster
\end{tabular}


Tabel 1. Klasifikasi pelanggan yang melakukan pencabutan layanan Indihome (lanjutan)

Segmen ke-24 Jenis pencabutan layanan New Indihome pengguna UseeTv Indihome $S d$, UseeTv Indihome $H d$, Usee Starter Pack $S d$, UseeTv Gold Hd, dan UseeTv Gold Sd oleh kategori pelanggan Bisnis, Apartment, Dinas Rumah, Pemerintah/TNI/Polri, serta Telum

\section{Segmen ke-25 Jenis pencabutan layana Inet_Tv}

Berdasarkan diagram pohon hasil analisis CHAID juga menerangkan bahwa pada node teratas diketahui jumlah total pelanggan yang melakukan pencabutan adalah 58.451 pelanggan, terdiri dari 11.137 pelanggan $(19,7 \%)$ dengan status pecabutan churn out dan 45.314 pelanggan $(80,3 \%)$ dengan status pencabutan downgrade.

Tabel 2. Persentase Jenis Pencabutan per Segmen

\begin{tabular}{ccccc}
\hline \multirow{2}{*}{ Segmen ke- } & \multicolumn{2}{c}{ Downgrade } & \multicolumn{2}{c}{ Churn Out } \\
\cline { 2 - 5 } & Persentase (\%) & Jumlah & Persentase (\%) & Jumlah \\
\hline 1 & 91.2 & 3829 & 8.8 & 370 \\
\hline 2 & 95.7 & 425 & 4.3 & 19 \\
\hline 3 & 99.5 & 199 & 0.5 & 1 \\
\hline 4 & 94.3 & 4273 & 5.7 & 259 \\
\hline 5 & 86.2 & 11007 & 13.8 & 1760 \\
\hline 6 & 93.7 & 887 & 6.3 & 50 \\
\hline 7 & 77.9 & 205 & 22.1 & 968 \\
\hline 8 & 66.9 & 1960 & 33.1 & - \\
\hline 9 & 100.0 & 59 & - & 423 \\
\hline 10 & 90.5 & 4047 & 9.5 & 329 \\
\hline 11 & 99.5 & 393 & 27.6 & \\
\hline 12 & 72.4 & 862 & & \\
\hline
\end{tabular}


Tabel 2. Persentase Jenis Pencabutan per Segmen (lanjutan)

\begin{tabular}{ccccc}
\hline 13 & 87.5 & 308 & 12.5 & 44 \\
\hline 14 & 77.8 & 2172 & 22.2 & 620 \\
\hline 15 & 94.0 & 63 & 6.0 & 4 \\
\hline 16 & 65.4 & 2917 & 34.6 & 1544 \\
\hline 17 & 82.5 & 113 & 17.5 & 24 \\
\hline 18 & 68.4 & 2097 & 31.6 & 967 \\
\hline 19 & 82.4 & 103 & 17.6 & 22 \\
\hline 20 & 96.4 & 53 & 3.6 & 658 \\
\hline 21 & 74.7 & 1945 & 25.3 & 217 \\
\hline 22 & 70.8 & 525 & 29.2 & 64 \\
\hline 23 & 62.6 & 4509 & 37.4 & 6 \\
\hline 24 & 74.9 & 250 & 25.1 & 11137 \\
\hline 25 & 99.7 & 2113 & 0.3 & \\
\hline Total & & 45314 & & \\
\hline
\end{tabular}

\section{Kesimpulan}

Berdasarkan hasil klasifikasi menggunakan metode Chi-Squared Automatic Interaction Detection (CHAID) diperoleh 37 node dengan 25 node terminal yang berarti terdapat 25 klasifikasi pelanggan yang melakukan pencabutan dengan kategori downgrade dan churn out. Dengan jumlah pencabutan kategori downgrade sebanyak 45314 pelanggan dan jumlah pencabutan kategori churn out sebanyak 11137 pelanggan.

Jumlah pencabutan kategori downgrade terbanyak terdapat pada segmen ke-5 dengan jenis pencabutan layanan Indihome $2 P$ pengguna New UseeTv Entry HD, UseeTv Indihome Starer HD, dan UseeTv Indihome $H d$ oleh kategori pelanggan Residensial sejumlah 11007 pelanggan dan pencabutan dengan kategori churn out terbanyak terdapat pada segmen ke-23 dengan jenis pencabutan layanan New Indihome pengguna UseeTv Indihome Sd, UseeTv Indihome Hd, Usee Starter Pack Sd, UseeTv Gold Hd, dan UseeTv 
Gold Sd oleh kategori pelanggan Residensial serta Prime Cluster sejumlah 2696 pelanggan.

\section{Daftar Pustaka}

[1] Turban, E., J.E. Aronson dan T.P. Liang. Decision Support System and Intelligent Systems - 7th ed. Pearson Education, Inc. 2005. Dwi Prabantini (penterjemah). Sistem Pendukung Keputusan dan Sistem Cerdas. Penerbit ANDI. Yogyakarta. 2005.

[2] Santosa, B. Data Mining: Teknik Pemanfaatan Data untuk Keperluan Bisnis. Graha Ilmu. Yogyakarta. 2007.

[3] Larose, D.T. Discovering Knowledge in Data: An Introduction to Data Mining. John Willey \& Sons, Inc. 2005.

[4] Gorunescu, F. Data Mining Concept Model and Techniques. Berlin: Springer. ISBN 9783-642-19720-8. 2011.

[5] Bagozzi, R.P. Advanced Methods of Marketing Research. Blackwell Publishers Ltd., Oxford. 1994.

[6] Myers, J.H. Segmentation and Positioning for Strategic Marketing Decisions. American Marketing Association. Chicago. 1996.

[7] Kunto, Y.S. dan Hasana, S.N. Analisis CHAID Sebagai Alat Bantu Statistika Untuk Segmentasi Pasar, Jurnal Manajemen, Vol. 1 No. 2. Universitas Kristen Petra: Surabaya. 2006. 